\title{
An early rise in body temperature is related to unfavorable outcome after stroke: data from the PAIS study
}

\author{
Heleen M. den Hertog $\cdot H$. Bart van der Worp • \\ H. Maarten A. van Gemert • Ale Algra • L. Jaap Kappelle • \\ Jan van Gijn · Peter J. Koudstaal · Diederik W. J. Dippel
}

Received: 3 June 2010/Revised: 3 August 2010/Accepted: 13 September 2010/Published online: 30 September 2010

(C) The Author(s) 2010. This article is published with open access at Springerlink.com

\begin{abstract}
Subfebrile temperature or fever is present in about a third of patients on the first day after stroke onset and is associated with poor outcome. However, the temporal profile of this association is not well established. We aimed to assess the relationship between body temperature on admission as well as the change in body temperature from admission to $24 \mathrm{~h}$ thereafter and functional outcome and death. We analyzed data of 1,332 patients admitted within $12 \mathrm{~h}$ of stroke onset. The relation between body temperature on admission or the change in body temperature from admission to $24 \mathrm{~h}$ thereafter (adjusted for body temperature on admission) on the one hand and unfavorable outcome (death, or a modified Rankin Scale score $>2$ ) at 3 months on the other were expressed as odds ratio per $1.0^{\circ} \mathrm{C}$ increase in body temperature. Adjustments for potential confounders were made with a multiple logistic regression model. No relation was found between
\end{abstract}

On behalf of the PAIS investigators.

H. M. den Hertog ( $₫)$ · P. J. Koudstaal · D. W. J. Dippel Department of Neurology, Erasmus MC University Medical Center Rotterdam, PO Box 2040, 3000 CA Rotterdam, The Netherlands

e-mail: m.denhertog@erasmusmc.nl

H. B. van der Worp · A. Algra · L. J. Kappelle · J. van Gijn Department of Neurology, Rudolf Magnus Institute of Neuroscience, University Medical Center Utrecht, Utrecht, The Netherlands

H. M. A. van Gemert

Department of Neurology, Meander Medical Center, Amersfoort, The Netherlands

A. Algra

Julius Center for Health Sciences and Primary Care,

University Medical Center Utrecht, Utrecht, The Netherlands admission body temperature and poor outcome (aOR 1.06; 95\% CI 0.85-1.32) and death (aOR 1.23; 95\% CI $0.95-1.60)$. In contrast, increased body temperature in the first $24 \mathrm{~h}$ after stroke onset was associated with poor outcome (aOR 1.30; 95\% CI 1.05-1.63) and death (aOR 1.51; 95\% CI 1.15-1.98). An early rise in body temperature rather than high body temperature on admission is a risk factor for unfavorable outcome in patients with acute stroke.

Keywords Stroke $\cdot$ Body temperature $\cdot$ Clinical outcome

\section{Background}

Subfebrile temperature or fever is common in patients with acute stroke. Body temperatures over $37.5^{\circ} \mathrm{C}$ have been reported in up to a quarter of patients within the first $6 \mathrm{~h}$ [19], and in about a third at $24 \mathrm{~h}$ after stroke onset [7]. This elevation of body temperature may be a direct consequence of brain damage inflicted by stroke, or a result of an associated infection [8].

Increased body temperature markedly exacerbates neuronal injury in experimental models of cerebral ischemia [13]. An association between increased body temperature and poor outcome has also been shown in patients with acute stroke $[3,4,7,12,14-17,19-21,23]$. However, the temporal profile of this relation is not well established. Several prospective studies found that high body temperature on admission was associated with poor outcome [3, 7, $16,19,20,23]$. Others found that an increased body temperature within the first days after stroke onset was a prognostic factor for unfavorable outcome [4, 12, 20, 21].

The aim of our study was to assess the relationship between body temperature within the first $12 \mathrm{~h}$ after 
symptom onset, and the change in body temperature from admission to $24 \mathrm{~h}$ thereafter on the one hand, and functional outcome and death on the other, in a large sample of stroke patients.

\section{Methods}

All patients participated in the Paracetamol (Acetaminophen) In Stroke (PAIS) trial. The PAIS trial was a multicenter, randomized, placebo-controlled clinical trial of high-dose acetaminophen in patients with acute stroke [10]. In short, patients with ischemic stroke or intracerebral hemorrhage with no history of liver disease or significant pre-stroke impairment (grade on the modified Rankin Scale $(\mathrm{mRS}) \geq 2$ ) [22] were included within $12 \mathrm{~h}$ of symptom onset and treated with high-dose acetaminophen ( $6 \mathrm{~g}$ daily) or placebo for the next 3 days.

\section{Clinical characteristics}

Baseline clinical information included stroke severity assessed by means of the NIH Stroke Scale (NIHSS [6]), ischemic stroke subtype according to the TOAST classification [2], and cardiovascular risk factors. In addition, any infection that led to prolonged hospital stay or was life threatening was recorded. The diagnosis of infection was left with the treating physician.

\section{Body temperature}

Body temperature was measured with a tympanic or rectal thermometer within $12 \mathrm{~h}$ from stroke onset and $24 \mathrm{~h}$ later. In each patient, a similar method of thermometry was used at these two points in time.

\section{Outcome measures}

Poor outcome was defined as a grade of more than two on the mRS at 3 months from stroke onset. Scores on the mRS range from 0 (no symptoms at all) to 5 (severe disability); for statistical purposes, death has a score of six.

A secondary outcome measure was death at 3 months. Outcome assessment was blinded for body temperature.

\section{Statistical analysis}

Statistical analyses were performed with Stata/SE 9.2 for Windows (Statacorp, College Station, TX, USA). The relation between body temperature on admission and the change in body temperature from admission to $24 \mathrm{~h}$ thereafter (adjusted for admission body temperature) on the one hand and poor outcome or death on the other, was expressed as an odds ratio per $1.0^{\circ} \mathrm{C}$ increase in body temperature with a corresponding $95 \%$ confidence interval (CI), as estimated with logistic regression.

Adjustments were made with a multiple logistic regression model that included the following factors: age, sex, baseline NIHSS score, stroke type (ischemic stroke vs. intracerebral hemorrhage), ischemic stroke subtype (lacunar vs. non-lacunar infarction), treatment with rtPA, and the occurrence of infections. We performed additional analyses to account for the potential confounding effect of antipyretic treatment by stratifying for treatment with acetaminophen, which was the experimental drug treatment in the PAIS trial.

Furthermore, we assessed the relation between several clinical variables including stroke type, ischemic stroke subtype, and stroke severity (expressed in quartiles of the baseline NIHSS score) and the change in body temperature from baseline to $24 \mathrm{~h}$ thereafter (adjusted for admission body temperature) with multiple linear regression.

\section{Results}

Included into the PAIS trial were 1,400 patients with a clinical diagnosis of ischemic stroke or intracerebral hemorrhage. Of these patients, 68 were excluded from the present study either because the final diagnosis was not a stroke $(n=3)$ or because body temperature at $24 \mathrm{~h}$ was not recorded $(n=65)$.

In the remaining 1,332 patients, mean age was 70 years (SD 13), 56\% of the patients were male, and $88 \%$ had an ischemic stroke (Table 1). The infarction was of the lacunar type in 193 patients $(17 \%)$. The median score on the NIHSS scale was 6 (range 0-30). Median time from stroke onset to measurement of the admission body temperature was $6 \mathrm{~h}$ (IQR 240-540). A total of 660 patients (50\%) was treated with acetaminophen.

The mean body temperature was $36.9^{\circ} \mathrm{C}$ (SD 0.6) on admission, and $37.1^{\circ} \mathrm{C}$ (SD 0.7) $24 \mathrm{~h}$ later. Body temperature over $37.5^{\circ} \mathrm{C}$ was observed in 160 patients $(12 \%)$ on admission and in 298 (22\%) $24 \mathrm{~h}$ later. The increase in body temperature from baseline to $24 \mathrm{~h}$ thereafter was larger in patients with body temperatures of $37.0^{\circ} \mathrm{C}$ or less than in those with body temperatures over $37.0^{\circ} \mathrm{C}$ (Fig. 1).

After 24 h, 96 of 660 patients (15\%) treated with acetaminophen and 202 of 672 patients $(30 \%)$ on placebo had a body temperature over $37.5^{\circ} \mathrm{C}$ (difference $15 \%$; 95\% CI 11-19\%). Treatment with acetaminophen was associated 
Table 1 Baseline clinical characteristics of the patients $(n=1,332)$

\begin{tabular}{|c|c|}
\hline \multicolumn{2}{|l|}{ Demographics } \\
\hline Mean (SD) age (years) & $70(13)$ \\
\hline Sex (male) & $749(56 \%)$ \\
\hline \multicolumn{2}{|l|}{ Cardiovascular risk factors } \\
\hline Hypertension & $652(49 \%)$ \\
\hline Atrial fibrillation & $198(15 \%)$ \\
\hline Diabetes mellitus & $195(15 \%)$ \\
\hline Current cigarette smoking & $390(29 \%)$ \\
\hline Hypercholesterolemia & $332(25 \%)$ \\
\hline \multicolumn{2}{|l|}{ Medical history } \\
\hline Stroke & $267(20 \%)$ \\
\hline Myocardial infarction & $155(12 \%)$ \\
\hline Peripheral vascular disease & $128(10 \%)$ \\
\hline \multicolumn{2}{|l|}{ Stroke type } \\
\hline Ischemic stroke & $1,169(88 \%)$ \\
\hline \multicolumn{2}{|l|}{ Ischemic stroke subtype $^{a}$} \\
\hline Large vessel disease ( $\geq 50 \%$ stenosis) & $146(12 \%)$ \\
\hline Cardiac source of embolism & $216(18 \%)$ \\
\hline Small vessel occlusion & $193(17 \%)$ \\
\hline Other determined etiology & $90(8 \%)$ \\
\hline Undetermined & $477(41 \%)$ \\
\hline Missing information & $47(4 \%)$ \\
\hline \multicolumn{2}{|l|}{ Stroke severity } \\
\hline Median (range) NIHSS score ${ }^{b}$ & $6(0-30)$ \\
\hline \multicolumn{2}{|l|}{ Physical examination } \\
\hline Mean (SD) body temperature $\left({ }^{\circ} \mathrm{C}\right)$ & $36.9(0.6)$ \\
\hline $\begin{array}{l}\text { Median (IQR) time from stroke onset } \\
\text { to measurement of baseline body } \\
\text { temperature (min) }\end{array}$ & $360(240-540)$ \\
\hline \multicolumn{2}{|l|}{ Treatment } \\
\hline Acetaminophen & $660(50 \%)$ \\
\hline Intravenous alteplase & $281(21 \%)$ \\
\hline
\end{tabular}

a Based on the trial of ORG 10172 in Acute Stroke Therapy (TOAST) criteria

${ }^{\mathrm{b}}$ Scores on the National Institutes of Health Stroke Scale (NIHSS)

with a $0.26^{\circ} \mathrm{C}(95 \% \mathrm{CI}, 0.18-0.31)$ reduction in mean body temperature measured $24 \mathrm{~h}$ after admission.

Four of the 160 patients (3\%) with baseline body temperatures over $37.5^{\circ} \mathrm{C}$ and 24 of 298 patients (8\%) with body temperatures over $37.5^{\circ} \mathrm{C} 24 \mathrm{~h}$ later developed an infection during hospitalization.

The proportion of patients with admission body temperatures over $37.5^{\circ} \mathrm{C}$ was similar in patients with ischemic stroke [145/1,169 (12\%) [and in those with intracerebral hemorrhage [16/163 (10\%)] and also in patients with nonlacunar infarction [136/1,139 (10\%)] and lacunar infarction [24/193 (12\%)]. However, the increase in body temperature from admission to $24 \mathrm{~h}$ thereafter was $0.24^{\circ} \mathrm{C}$ larger $(95 \%$ CI, 0.14-0.33) in patients with non-lacunar infarction than in those with lacunar infarction and also $0.33^{\circ} \mathrm{C}(95 \% \mathrm{CI}$,

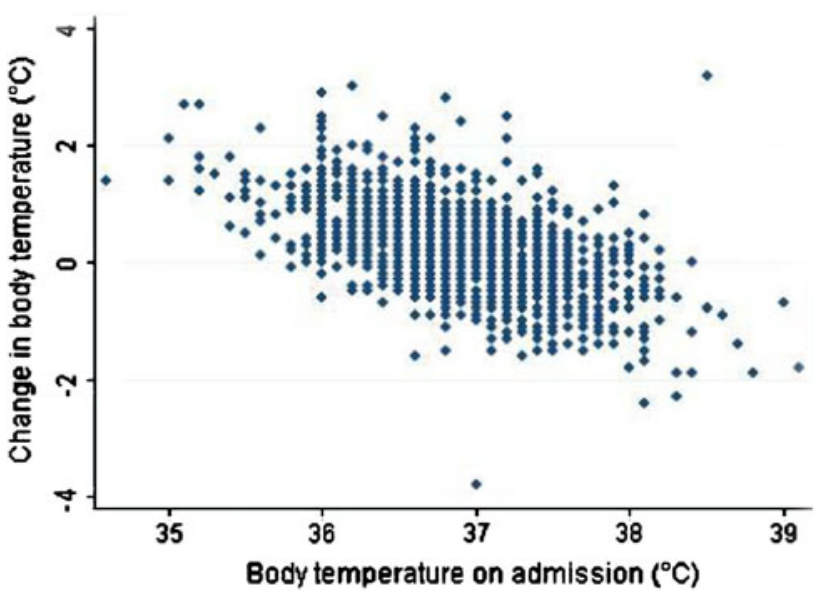

Fig. 1 The change in body temperature in the first $24 \mathrm{~h}$ from admission to $24 \mathrm{~h}$ thereafter $\left({ }^{\circ} \mathrm{C}\right)$ as a function of body temperature on admission $\left({ }^{\circ} \mathrm{C}\right)$

0.23-0.44) larger in patients with intracerebral hemorrhage than in patients with ischemic stroke.

We did not observe a proportional increase in the association between stroke severity and body temperature on admission. However, in the highest quartile of the NIHSS score (NIHSS score $\geq 13$ ), baseline body temperature was $0.20^{\circ} \mathrm{C}(95 \% \mathrm{CI}, 0.12-0.27)$ lower than body temperature in the lower quartiles of the NIHSS score (NIHSS <13) (Fig. 2). Body temperature $24 \mathrm{~h}$ later was associated with baseline stroke severity. For every quartile of the NIHSS score, body temperature at $24 \mathrm{~h}$ rose on average with $0.16^{\circ} \mathrm{C}(95 \% \mathrm{CI}, 0.13-0.19)$ (Fig. 2).

Body temperature on admission was not related to poor outcome or death (Table 2). An increased body temperature in the first $24 \mathrm{~h}$ after admission, however, was associated with poor outcome or death at 3 months (Table 2). Adjustment for potential confounders slightly attenuated this association (Table 2). An additional stratified analysis to account for the potentially modifying effect of treatment

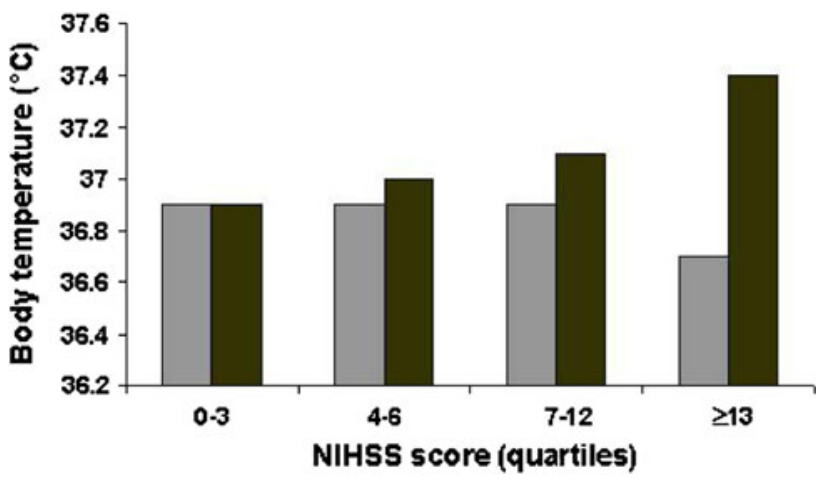

Fig. 2 Stroke severity (quartiles) and body temperature within $12 \mathrm{~h}$ from stroke onset, (grey bars) and $24 \mathrm{~h}$ later (black bars) 
Table 2 Association of body temperature with poor outcome or death at 3 months

\begin{tabular}{llllll}
\hline & Poor outcome & Overall & Overall & aOR $(95 \% \mathrm{CI})^{\mathrm{ab}}$ \\
\cline { 5 - 6 } & & OR $(95 \% \mathrm{CI})^{\mathrm{a}}$ & $\mathrm{aOR}(95 \% \mathrm{CI})^{\mathrm{ab}}$ & Acetaminophen & Placebo \\
\hline Within 12 h from stroke onset & $\mathrm{mRS}>2(n=663)$ & $0.82(0.68-0.98)$ & $1.06(0.85-1.32)$ & $0.91(0.66-1.26)$ & $1.19(0.87-1.64)$ \\
& Death $(n=218)$ & $0.87(0.68-1.12)$ & $1.23(0.95-1.60)$ & $1.10(0.74-1.63)$ & $1.37(0.96-1.96)$ \\
Change from admission to $24 \mathrm{~h}^{\mathrm{c}}$ & $\mathrm{mRS}>2(n=663)$ & $1.98(1.65-2.39)$ & $1.30(1.05-1.63)$ & $1.22(0.86-1.73)$ & $1.35(1.00-1.83)$ \\
& Death $(n=218)$ & $2.36(1.86-2.99)$ & $1.51(1.15-1.98)$ & $1.51(0.97-2.36)$ & $1.61(1.11-2.31)$ \\
\hline
\end{tabular}

${ }^{a}$ Per $1.0^{\circ}$ Celsius increase of body temperature

b Adjusted for age, sex, NIHSS score, stroke type, ischemic stroke subtype, treatment with rtPA, and occurrence of infections

c Adjusted for body temperature on admission

with acetaminophen did not affect the association (Table 2).

After exclusion of patients who developed an infection during the first 2 weeks after stroke onset, the adjusted odds ratio for poor outcome was 1.30 (95\% CI 1.04-1.63), and for death 1.50 (95\% CI 1.12-2.00).

Figure 3 illustrates the strength of the association between the change in body temperature from admission to $24 \mathrm{~h}$ thereafter and poor outcome. The absolute difference in the risk of poor outcome between patients in the lowest and patients in the highest body temperature category is more than $20 \%$.

\section{Discussion}

Our results do not confirm the previously reported association between high body temperature on admission and unfavorable outcome in patients with acute stroke. However, patients with increased body temperatures in the first $24 \mathrm{~h}$ after admission did have an increased risk of poor functional outcome or death at 3 months.

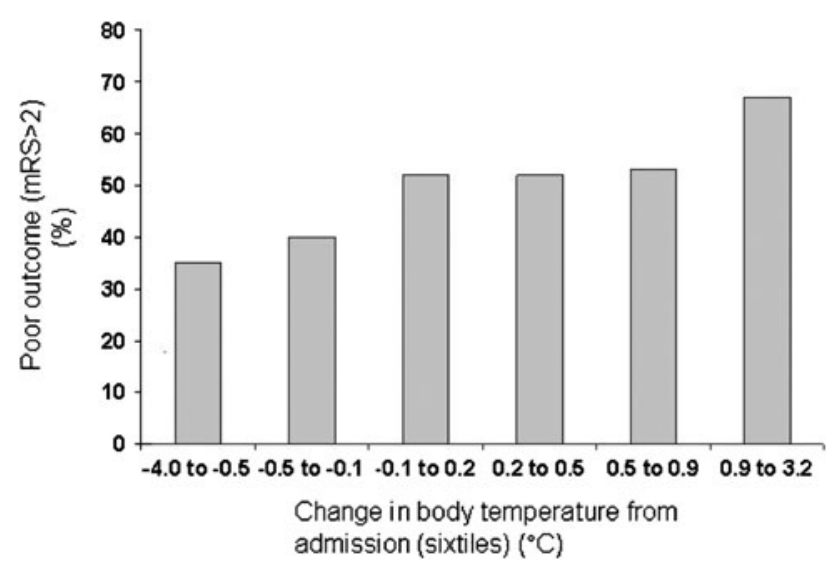

Fig. 3 Probability of poor outcome $(\mathrm{mRS}>2)$ at 3 months in relation to change in body temperature from baseline to $24 \mathrm{~h}$ thereafter (sixtiles) $\left({ }^{\circ} \mathrm{C}\right)$
Before these results can be interpreted, some methodological issues have to be discussed. First, one of the strengths of our study is its large sample size. Other strengths include robust outcome measures and detailed information on confounders. Second, PAIS was a randomized double-blind placebo-controlled trial that addressed the question of whether temperature reduction by acetaminophen would improve outcome in patients with acute stroke [10]. Half of the study population was treated with acetaminophen in a daily dose of $6 \mathrm{~g}$ for three consecutive days. As a result, body temperature at $24 \mathrm{~h}$ after admission was lowered and fewer patients may have experienced a poor outcome, although the overall effect of acetaminophen on outcome was not statistically significant. We did separate regression analyses in the patients treated with acetaminophen and those allocated to placebo. The estimates of the association between the change in body temperature from admission to $24 \mathrm{~h}$ thereafter and outcome were similar in the two groups, suggesting that the study population could be analyzed as one group.

A third issue is that we only recorded body temperature at two points in time, i.e., within $12 \mathrm{~h}$ from symptom onset and $24 \mathrm{~h}$ later and did not repeat measurements of body temperature. As a consequence, it might be more difficult to compare our results with the results of previous studies.

Finally, relatively few patients with very severe stroke were included, possibly because we did not specify a lower NIHSS score limit in the eligibility criteria of the PAIS trial. However, our results showed that patients with more severe strokes had higher body temperatures at $24 \mathrm{~h}$ after admission, and thereby underrepresentation of patients with severe strokes potentially weakens rather than exaggerates the observed relation between body temperature at $24 \mathrm{~h}$ after admission and poor outcome.

Previous studies have found that increased body temperature within $6 \mathrm{~h}$ up to at least $24 \mathrm{~h}$ after stroke onset is an independent prognostic factor for poor outcome $[3,4,7,12$, 14-17, 19-21, 23]. However, the temporal profile of this association is still under debate. Several studies showed that 
high body temperature on admission was associated with poor outcome $[3,7,15]$. In three of these, no adjustments were made for baseline stroke severity assessed with validated stroke scales $[2,5,8]$. In a prospective study of 390 patients with either ischemic stroke or intracerebral hemorrhage admitted within $6 \mathrm{~h}$ of symptom onset, the odds of poor outcome doubled for every degree of Celsius increase in baseline body temperature [19]. We found that patients with severe stroke had relatively low body temperatures at baseline, possibly because of a faster loss of body temperature before hospital admission as a result of less muscle activity. This finding might explain in part that body temperature on admission was not associated with clinical outcome.

A prospective study of 725 patients admitted within $6 \mathrm{~h}$ of symptom onset found a relation between increased body temperature at 10-12 h after stroke onset and poor outcome, but no relationship between body temperature on admission and poor outcome was found [4]. Although these results seem contradictory to our findings, our results indeed suggest that increased body temperature in the first $24 \mathrm{~h}$ after admission rather than body temperature on admission is an important prognostic factor for clinical outcome after stroke. In line with our results, a recent study of 5,305 patients with ischemic stroke from the Virtual International Stroke Trials Archive found that an increase in body temperature from baseline rather than high body temperature on admission was a strong risk factor for poor outcome [20]. As the data came from different randomized trials, body temperature was dichotomized at $37.2^{\circ} \mathrm{C}$ and follow-up temperatures were only available for a third of the patients.

Two others showed that increased body temperature relative to baseline in the first 24-72 h after stroke onset was associated with unfavorable outcome [12, 21]. These studies included only patients with intracerebral hemorrhage [21] or patients with ischemic stroke treated with intravenous thrombolysis [12].

In a recent prospective study with 250 patients with ischemic stroke, the association between body temperature and unfavorable outcome was dependent on treatment with alteplase [17]. High body temperature in the first $6 \mathrm{~h}$ from symptom onset was associated with favorable outcome in patients treated with alteplase, and low body temperature was associated with favorable prognosis in those not treated with alteplase. In the present study, we could not confirm that the association between body temperature and outcome is dependent on treatment with rtPA.

Increased body temperature may be attributed to a systemic inflammatory response following ischemic stroke or to accompanying infections. In addition, it has been suggested that increased body temperature indicates hypothalamic damage following stroke [18]. The mechanisms of the association between an early rise in body temperature and poor outcome remain speculative. Secondary infections are common in the first week of stroke and are associated with poor outcome, but they usually occur more than $12 \mathrm{~h}$ after stroke onset [11]. In our study, only $8 \%$ of patients with body temperatures over $37.5^{\circ} \mathrm{C}$ developed an infection during hospitalization. Besides, the relationship between body temperature at $24 \mathrm{~h}$ after admission and poor outcome was independent of the occurrence of infections. Furthermore, exclusion of patients developing an early infection during hospitalization did not substantially affect the relation between body temperature and poor functional outcome or death. Therefore, infections cannot account for the observed relation between temperature and outcome.

The change in body temperature from admission was associated with baseline stroke severity. One may argue that increased body temperature does not accelerate the ischemic cascade, but merely reflects extensive cerebral damage and, thereby, of poor outcome. However, the relation between increased body temperature and poor outcome was independent of baseline stroke severity.

Our results provide a rationale for the hypothesis that prevention of an early rise in body temperature could reduce death and improve functional outcome. Guidelines for the treatment of patients with acute ischemic stroke [1] or intracerebral hemorrhage [5] recommend the administration of antipyretic medication in case of fever or a temperature above $37.5^{\circ} \mathrm{C}$. This might be too late, as the rise in body temperature has already occurred, and the time period in which the brain lesion is most vulnerable has subsided. On the other hand, there is still no convincing evidence from randomized trials that strategies to prevent or treat elevated body temperature reduce case fatality and improve functional outcome after stroke $[9,10]$.

Acknowledgments The PAIS trial was sponsored by the Netherlands Heart Foundation, grant number 2002B148. We are grateful to all patients, secretaries, and neurologists who contributed to this study. All patients participated in the PAIS trial; written informed consent was obtained from all patients or from their legal representatives for inclusion in the trial and for follow-up. The study was performed in accordance with the ethical standards laid down in the 1964 Declaration of Helsinki.

\section{Conflict of interest None.}

Open Access This article is distributed under the terms of the Creative Commons Attribution Noncommercial License which permits any noncommercial use, distribution, and reproduction in any medium, provided the original author(s) and source are credited.

\section{Appendix: Participating centers with names of investigators}

Meander MC Amersfoort (HMA van Gemert), Erasmus MC Rotterdam (DWJ Dippel), UMC Utrecht (HB van der 
Worp), Sint Fransicus Gasthuis Rotterdam (FH Vermeij), Slotervaart Ziekenhuis Amsterdam (VIH Kwa), Gelre ziekenhuizen Apeldoorn (HP Bienfait), TweeSteden ziekenhuis Tilburg (BPW Jansen), Sint Elisabeth Ziekenhuis Tilburg (PLM de Kort), Westfriesgasthuis Hoorn (TC van der Ree), Maasstad ziekenhuis Rotterdam (R Saxena), Ziekenhuis Bethesda Hoogeveen (PG Oomes), Dirksland Ziekenhuis Dirksland (UW Huisman), Sint Lucas Andreas Ziekenhuis Amsterdam (EJ Wouda), Martini Ziekenhuis Groningen (C Bouwsma), Catharina Ziekenhuis Eindhoven (K Keizer) Albert Schweitzer ziekenhuis Dordrecht (RP Kleyweg/H Kerkhoff), Amphia Ziekenhuis Breda (HBC Verbiest/SLM Bakker), Rijnland Ziekenhuis Leiderdorp (ELLM De Schryver), Diakonessenhuis Utrecht (RCJM Donders), Slingeland Ziekenhuis Doetinchem (RA van der Kruijk), IJsselland Ziekenhuis Capelle aan den Ijssel (J Heerema), Jeroen Bosch Ziekenhuis Den Bosch (RAJAM Bernsen), Ziekenhuis Hilversum Hilversum (D Herderschêe), Diaconessenhuis Meppel (EJW Keuter), Vlietlandziekenhuis Schiedam (WC Baart), Spaarne Ziekenhuis Hoofddorp (RJ Meijer), Beatrixziekenhuis Gorinchem (RB Alting van Geusau), Streekziekenhuis Koningin Beatrix Winterswijk (JP de Ruiter), Wilhelmina Ziekenhuis Assen (JN Wessel/AE Bollen).

\section{References}

1. Adams HP Jr, del ZG, Alberts MJ, Bhatt DL, Brass L, Furlan A, Grubb RL, Higashida RT, Jauch EC, Kidwell C, Lyden PD, Morgenstern LB, Qureshi AI, Rosenwasser RH, Scott PA, Wijdicks EF (2007) Guidelines for the early management of adults with ischemic stroke: a guideline from the American Heart Association/American Stroke Association Stroke Council, Clinical Cardiology Council, Cardiovascular Radiology and Intervention Council, and the Atherosclerotic Peripheral Vascular Disease and Quality of Care Outcomes in Research Interdisciplinary Working Groups: The American Academy of Neurology affirms the value of this guideline as an educational tool for neurologists. Circulation 115:e478-e534

2. Adams HPJ, Bendixen BH, Kappelle LJ, Biller J, Love BB, Gordon DL, Marsh EE (1993) Classification of subtype of acute ischemic stroke. Definitions for use in a multicenter clinical trial. TOAST. Trial of Org 10172 in Acute Stroke Treatment. Stroke 24:35-41

3. Azzimondi G, Bassein L, Nonino F, Fiorani L, Vignatelli L, Re G, D'Alessandro R (1995) Fever in acute stroke worsens prognosis. A prospective study. Stroke 26:2040-2043

4. Boysen G, Christensen H (2001) Stroke severity determines body temperature in acute stroke. Stroke 32:413-417

5. Broderick JP, Adams HP Jr, Barsan W, Feinberg W, Feldmann E, Grotta J, Kase C, Krieger D, Mayberg M, Tilley B, Zabramski JM, Zuccarello M (1999) Guidelines for the management of spontaneous intracerebral hemorrhage: A statement for healthcare professionals from a special writing group of the Stroke Council, American Heart Association. Stroke 30:905-915

6. Brott T, Adams HP Jr, Olinger CP, Marler JR, Barsan WG, Biller J, Spilker J, Holleran R, Eberle R, Hertzberg V (1989) Measurements of acute cerebral infarction: a clinical examination scale. Stroke 20:864-870

7. Castillo J, Davalos A, Marrugat J, Noya M (1998) Timing for fever-related brain damage in acute ischemic stroke. Stroke 29:2455-2460

8. den Hertog H., van der WB, van GM, Dippel D (2007) Therapeutic hypothermia in acute ischemic stroke. Expert Rev Neurother 7:155-164

9. den Hertog HM, van der Worp HB, Tseng MC, Dippel DW (2009) Cooling therapy for acute stroke. Cochrane Database Syst Rev 21:1

10. den Hertog HM, van der Worp HB, van Gemert HM, Algra A, Kappelle LJ, van GJ, Koudstaal PJ, Dippel DW (2009) The Paracetamol (Acetaminophen) In Stroke (PAIS) trial: a multicentre, randomised, placebo-controlled, phase III trial. Lancet Neurol 8:434-440

11. Emsley HC, Hopkins SJ (2008) Acute ischaemic stroke and infection: recent and emerging concepts. Lancet Neurol 7:341-353

12. Ernon L, Schrooten M, Thijs V (2006) Body temperature and outcome after stroke thrombolysis. Acta Neurol Scand 114:23-28

13. Ginsberg MD, Busto R (1998) Combating hyperthermia in acute stroke: a significant clinical concern. Stroke 29:529-534

14. Hajat C, Hajat S, Sharma P (2000) Effects of poststroke pyrexia on stroke outcome: a meta-analysis of studies in patients. Stroke 31:410-414

15. Hindfelt B (1976) The prognostic significance of subfebrility and fever in ischaemic cerebral infarction. Acta Neurol Scand 53:72-79

16. Jorgensen HS, Reith J, Pedersen PM, Nakayama H, Olsen TS (1996) Body temperature and outcome in stroke patients. Lancet 348:193

17. Naess H, Idicula T, Lagallo N, Brogger J, Waje-Andreassen U, Thomassen L (2010) Inverse relationship of baseline body temperature and outcome between ischemic stroke patients treated and not treated with thrombolysis: the Bergen stroke study. Acta Neurol Scand Epub

18. Przelomski MM, Roth RM, Gleckman RA, Marcus EM (1986) Fever in the wake of a stroke. Neurology 36:427-429

19. Reith J, Jorgensen HS, Pedersen PM, Nakayama H, Raaschou HO, Jeppesen LL, Olsen TS (1996) Body temperature in acute stroke: relation to stroke severity, infarct size, mortality, and outcome. Lancet 347:422-425

20. Saini M, Saqqur M, Kamruzzaman A, Lees KR, Shuaib A (2009) Effect of hyperthermia on prognosis after acute ischemic stroke. Stroke 40:3051-3059

21. Schwarz S, Hafner K, Aschoff A, Schwab S (2000) Incidence and prognostic significance of fever following intracerebral hemorrhage. Neurology 54:354-361

22. van Swieten JC, Koudstaal PJ, Visser MC, Schouten HJ, van Gijn J (1988) Interobserver agreement for the assessment of handicap in stroke patients. Stroke 19:604-607

23. Wang Y, Lim LL, Levi C, Heller RF, Fisher J (2000) Influence of admission body temperature on stroke mortality. Stroke 31:404-409 